\title{
EDUCATIONAL NEEDS OF PRIMARY HEALTH CARE NURSES ON PALLIATIVE CARE
}

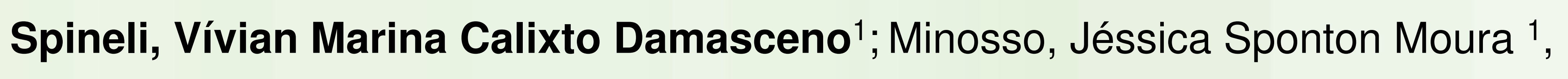

Costa, Gislaine Desani ${ }^{1}$; Oliveira Maria Amélia de Campos ${ }^{1}$.

Corresponding author: Vívian Spineli - vivianmarina@usp.br

\section{BACKGROUND}

Palliative care (CP) should not be considered an option, but astrategic care related to prevention, early detection and treatmentof Chronic diseases that threaten life and that affect patients and their families. The education of primary health care nurses $(\mathrm{PHC})$ in $\mathrm{CP}$ becomes necessary to provide comfort and relieve the suffering of those who need.

\section{OBJECTIVE}

To verify the needs of education in PC of nurses working in PHC in Brazil.

\section{METHOD}

This is a descriptive and exploratory study with a qualitative approach. For data collection, 19 focal groups were performed, with the participation of 183 nurses working in Basic Health Facilities and/or the Family Health Strategy of 19 municipalities in the South and Southwest of Minas Gerais, Brazil, with a mean of 9.6 nurses per group. The ethical and legal aspects for research with human beings in Brazil were preserved. The corpus of analysis of the study was formed by the data obtained in the focal groups and analyzed according to thematic analysis, performed in three stages: pre-analysis, content exploration, outcome treatment and interpretation; in light of Katharine Kolcaba's theory of comfort.

\section{RESULTS}

The data treatment and interpretation has allowed the categorization of these outcomes into specific themes. Such themes represent the needs of education in PC, according to the participating nurses. Among themes which were highlighted themselves: The process of communication and care in the end of life phase as fundamental aspects to the professional's education to provide relationship of trust, support in situations of fragility and suffering, and to avoid the distancing between the professional, the patient and the family. This was evidenced in the following speech:

"What we need to keep in mind is that we have all the clues that this patient knew what was happening to her. Then she hid on one side and the family hid from the other, so it's something of a chronic disease, which was limiting life and that everyone there stayed in that darkness and no one could argue about the process of her death and the process of dying and grief and I have the possibility of working...? How would it be if I sat down and talked to this Family..." Focal Group 11

\section{DISCUSSION}

The lack of preparation to communicate and face situations of physical, emotional, social and spiritual suffering, especially in the end of life phase, corroborates that nurses have difficulties to provide comfort to the patient and his/her family in all these dimensions

\section{CONCLUSION}

The identification of the needs of education in Palliative Care of nurses from PHC contributes to the elaboration of proposals of education in PC. 